\title{
Constructing an Automobile Color Matching Model
}

\author{
Tatsumi Shinogi ${ }^{1}$, Saki Aihara ${ }^{2}$, Kakuro Amasaka ${ }^{3}$ \\ ${ }^{I}$ (Aoyama Gakuin University, Japan) \\ 2 (Aoyama Gakuin University, Japan) \\ 3 (Aoyama Gakuin University, Japan)
}

\begin{abstract}
As a method of supporting idea generation in automobile product development, the authors have constructed the Automobile Color Matching Model (ACMM), which is a model for matching automobile exterior and interior colors while taking into account consumer preferences. The actual approach for the research was to first determine the parts relevant to automobile color matching by using an eye camera and an electroencephalograph to observe the responses of women in their twenties, who were the subjects of the research. Next, a customer preference survey was conducted and the research subjects' preferences were analyzed by using cluster analysis to categorize the research subjects according to their preferences and using principal component analysis to identify sensory words that describe requirements for automobiles. Then, color surveys were conducted for each preference group, and the obtained data was analyzed using quantification method type III to identify key colors. Analytic hierarchy process (AHP) was then used to conduct automobile color matching. The effectiveness of the resulting Automobile Color Matching Model (ACMM) has been verified and the required results have been attained.
\end{abstract}

Keywords: Decision Modeling \& Theory, Product Design \& Development

\section{Introduction}

One of the critical requirements faced by Japanese industries in the $21^{\text {st }}$ century is a methodology for creating attractive products. A typical example of this would be the automobile industry. In the development of new products, it is essential for an automobile manufacturer to accurately identify the consumers' thoughts and values, and incorporate them into its products. For this purpose, it is important to convert the consumers' feelings (tacit knowledge) into verbalized knowledge (images and concepts). It is also important to apply a customer science approach and incorporate such knowledge into design drawings as explicit knowledge through a process called "designing" (scientific representation and processing of consumer preferences). The aim of this research is to construct an Automobile Color Matching Model (ACMM) for matching exterior and interior colors while taking into account consumer preferences, as a method of supporting idea generation in automobile product development. The actual approach for the research was to first determine the parts relevant to automobile color matching by using an eye camera and an electroencephalograph to observe the responses of women in their twenties, who were the subjects of the research. Next, a customer preference survey was conducted and the research subjects' preferences were analyzed by using cluster analysis to categorize the research subjects according to their preferences and using principal component analysis to identify sensory words that describe requirements for automobiles. Then, color surveys were conducted for each preference group, and the obtained data was analyzed using quantification method type III to identify key colors. Analytic hierarchy process (AHP) was then used to conduct automobile color matching. The effectiveness of the resulting Automobile Color Matching Model (ACMM) has been verified and the required results have been attained.

\section{Research Background}

In today's world, companies with sustained growth in Japan or internationally commonly tend to have a cooperate management that gives top priority to consumers by identifying the consumers' requirements and incorporating that input into their product development. However, even in successful companies, behaviors of product developers and designers to appeal to consumers' tastes (i.e. idea generation as the basis of "designing") heavily depend on empirical skills, resulting in frequent merchandising through tacit process. Consequently, their workmanship merely depends on sales outcome in the market, and tends to be focused on tacit prescriptions, without sufficient review of the process and resulting feedback for future improvements [1-4]. Their primary concern is that, when they fortunately succeed, or unfortunately fail, their present business approach depends on operational steps and empirical methods specific to individuals, and it is unclear how the probability of success could be increased in the future.

In order to resolve this concern and dilemma, it is becoming a requirement to create a new method for supporting idea generation in strategic product development that could enhance insights and future outlooks, incorporate such a method into the processes from product planning to designing, and demonstrate the 
effectiveness thereof [5]. A number of different types of research have been undertaken concerning automobile design incorporating consumer preferences. Many studies concerning the exterior focus on the forms and colors of automobiles, while meters and colors have been popular themes of studies focused on the interior [6-11]. Nevertheless, no studies have been undertaken combining the exterior and the interior, and the methodology for combining exterior and interior colors is left as a theme for future studies. A status survey conducted on companies related to automobile design uncovered that not much emphasis has been placed on combination, and that the voice of the consumer has been interpreted based on intuition and experience, due to a lack of parameters for incorporating such inputs into design. These indicate the necessity of a model for matching colors of the exterior and interior. While consumers have had a declining desire to own automobiles in Japan, consumers in their 20s still have a relatively high appetite (Fig 1). In the meantime, as compared to their male counterparts, female consumers are more interested in design, both for the exterior and for the interior (Fig 2). These suggest that the automobile industry should primarily target female consumers in their 20 s to most effectively enhance the market.

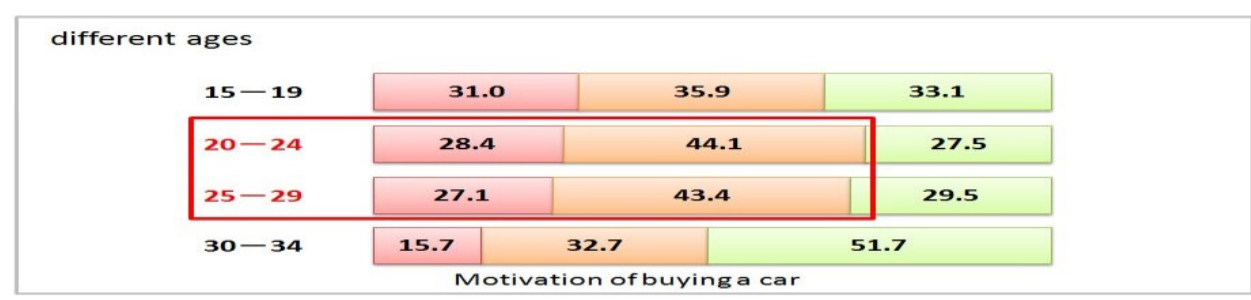

\begin{tabular}{|l|l|l|l}
\hline Want to buy $\quad$ If anything, want to buy $\quad$ Don't want to buy \\
\hline
\end{tabular}

Fig. 1. Will for buying a car

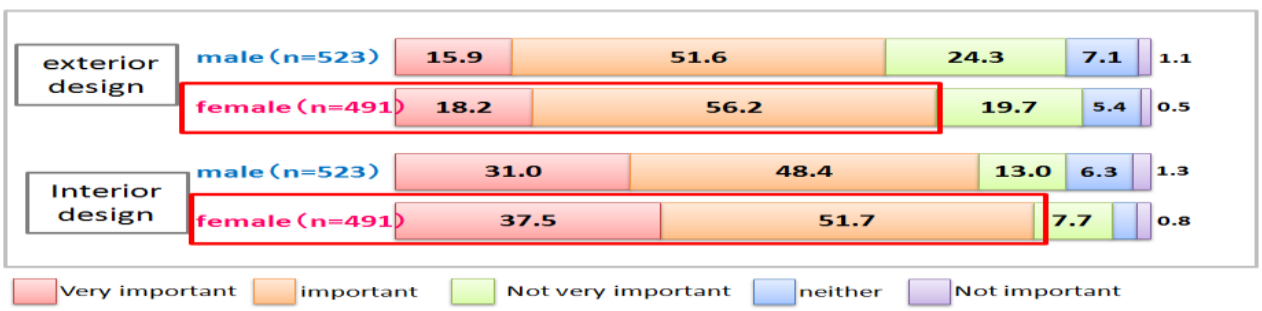

Fig. 2. Key point when buying a car

\section{Proposal Of ACMM, A Model For Matching Automobile Exterior And Interior Colors}

Thus the authors thought it necessary to visualize consumer preferences and link them to actual color matching, in order to enable color matching for the automobile exterior and interior. Therefore, the authors intended to establish Automobile Color Matching Model (ACMM), a model for matching automobile exterior and interior colors, as indicated in Fig 3. Details will follow in Steps 1 to 3. As was mentioned in the previous section, female consumers in their 20 s were selected as the scope of application for this model, because they lead to the most effective enhancement of market.

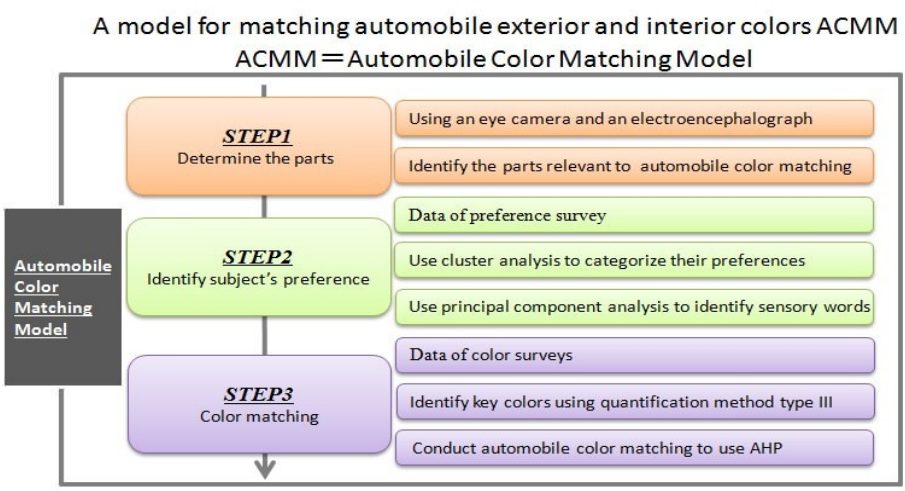

Fig. 3. Automobile color matching model (ACMM) 


\subsection{Step 1.Determining Targeted Parts for Color Matching}

In order to identify actual parts of automobiles observed by consumers, and changes in brainwaves during observation, data for analysis was collected from twelve females in their $20 \mathrm{~s}$, using an eye camera, for the analysis of human sight, and an electroencephalograph, for the measurement of brainwaves. First, an eye camera was used to analyze the time that eye sight resided on a particular part, and the parts of an automobile that were most focused on were identified. Colors in the graph closer to red indicate parts that were looked at more closely. The body, seats, steering wheel, and front panel were identified as the parts of an automobile that were most focused on (Fig 4).

Subsequently, brainwaves were measured to clarify brain reactions to the identified parts (body, seats, steering wheel, and front panel). The brainwaves were measured whenever the subject looked at each part for five seconds. The measurement results are indicated in Fig 5. When the subjects observed the body, seats or front panel, brain patterns substantially changed in many cases. Brainwaves did not show substantial changes only when the subjects looked at the steering wheel. This suggests that, although the subjects frequently looked at the steering wheel, they potentially paid little attention to it. Therefore, the body, seats, and front panel were selected as the parts targeted for color matching. Finally, the priority of each targeted part was identified through counting the number of times the subject looked at the targeted part area using the data collected with the eye camera. The priority was the largest for the body, followed by the seats and then the front panel (Fig 6).
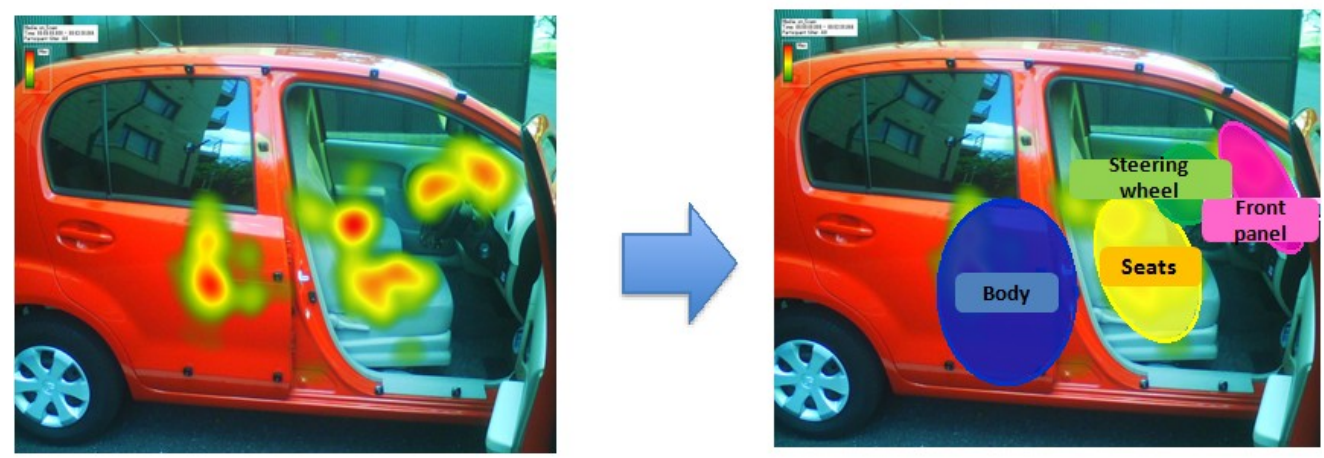

Fig. 4. The result of analyzing the time that eye sight resided on a particular part in eye camera

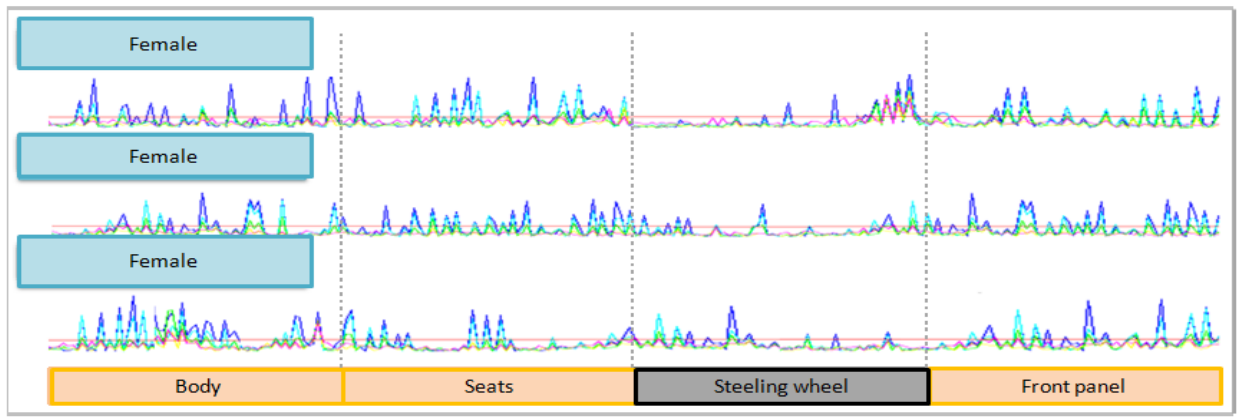

Fig. 5. The result of brainwaves

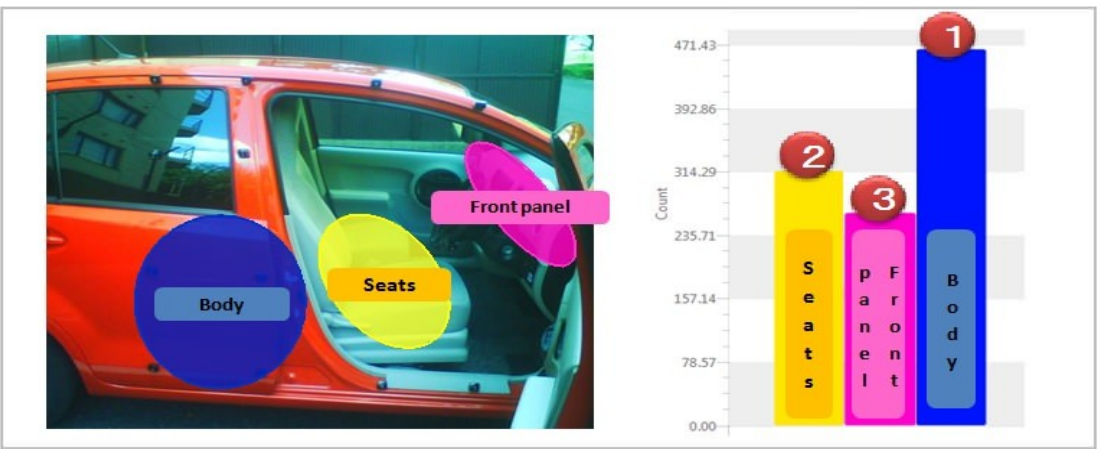

Fig. 6 . The priority of the parts in color matching 


\subsection{Step 2.Consumer Preference Survey}

A consumer preference survey was conducted to stratify consumer preferences, and to clarify what consumers wanted from automobile colors. A questionnaire was used as a means of the survey. The survey was conducted over fifty females in their 20s, asking 1) what automobile colors they liked, and 2) what magazines they were reading. In Question 1), twenty keywords were provided, as listed in Fig 7 (cute, cool, unique, refined, orthodox, chic, novel, sophisticated, futuristic, girly, classy, simple, traditional, fresh, fashionable, urban, conspicuous, clean, gentle, sporty), to represent images that the subjects wanted from automobile colors. Respondents were asked to answer rating each keyword on a scale of seven. In Question 2), respondents were supposed to freely describe their answers.

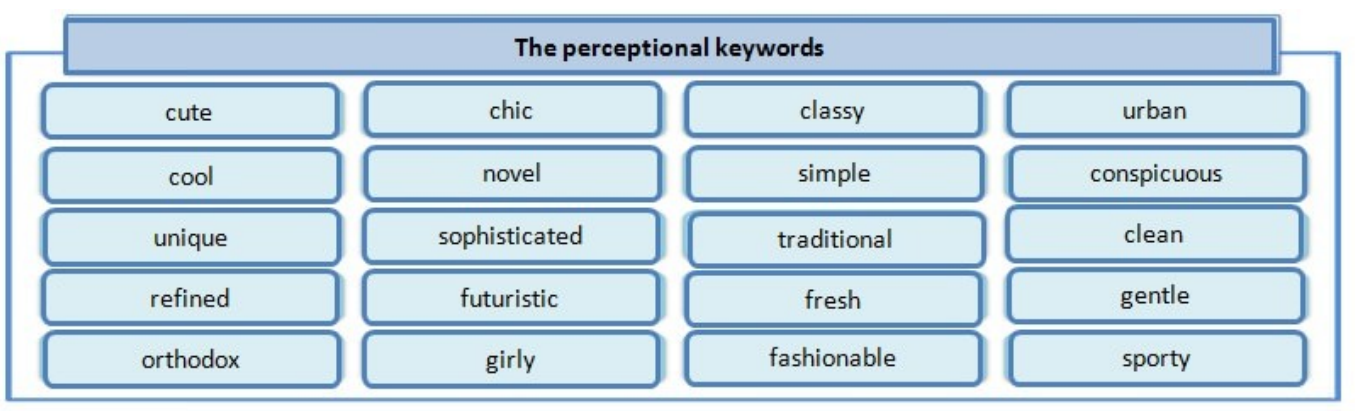

Fig. 7. The perceptional key words

\subsection{Classification of Preferences and Identification of Perceptional Keywords}

Cluster analysis was conducted to classify the subjects by their preferences. Responses to Question 1) were used as data for analysis. The analysis method applied sample classification, standardization, Ward's method, and Euclidean distance. Fig 8 (a) indicates the dendrogram for this analysis, suggesting that females in their 20s could be classified into Groups A through D. Freely described responses to Question 2) indicate that subjects in the same group prefer magazines for similar fashion styles. Based on these results, Group A was defined as 'Girlish', B as 'Elegant', C as 'Boyish', and D as 'Thrifty' (Fig 8 (b)).

Subsequently, principal component analysis was conducted using data collected in Question 1), in order to clarify relationships between consumer preferences and perceptional keywords. For the purpose of verifying the significance of each principal component, factor loading, which indicates correlation between the component and the original variant, was identified. Then a factor loading scatter diagram was formulated for Principal Component 1 and Principal Component 2. According to Principal Component 1, "conspicuous", "novel", "unique" and similar perceptional keywords indicated strong positive values, while "chic", "refined", "clean", etc. showed negative values. According to Principal Component 2, "sporty" and "cool" had positive values, in contrast to negative values for "cute" and "girly". These results can be interrupted as suggesting that, in the context of automobile colors, Principal Component 1 is an axis for preference to flamboyant or chic, while preference to cool or cute is indicated by the axis of Principal Component 2. Thus relationships between perceptional keywords and significances of principal components could be clarified.

Finally, the results of cluster analysis were compared with the results of principal component analysis, in order to clarify the characteristics of each group, and identify perceptional keywords by preference. Subjects were classified according to a scatter diagram formulated based on Principal Component 1 and Principal Component 2, and were compared to the groups defined in cluster analysis (Fig 9 (a)).The four groups based on cluster analysis could also be delineated on the principal component score scatter diagram. Therefore, by converting the principal component score scatter diagram into a factor score scatter diagram, perceptional keywords for each group could be picked up from its distribution area in the diagram. The identified keywords for 'Girlish' were "cute", "girly", "gentle" and "urban". For 'Elegant' the keywords were "refined", "classy", "chic" and "clean". For 'Boyish' the keywords were "cool", "sporty", "simple" and "orthodox"; and for 'Thrifty' they were "unique", "novel", "conspicuous", and "fashionable" (Fig 9 (b)). 

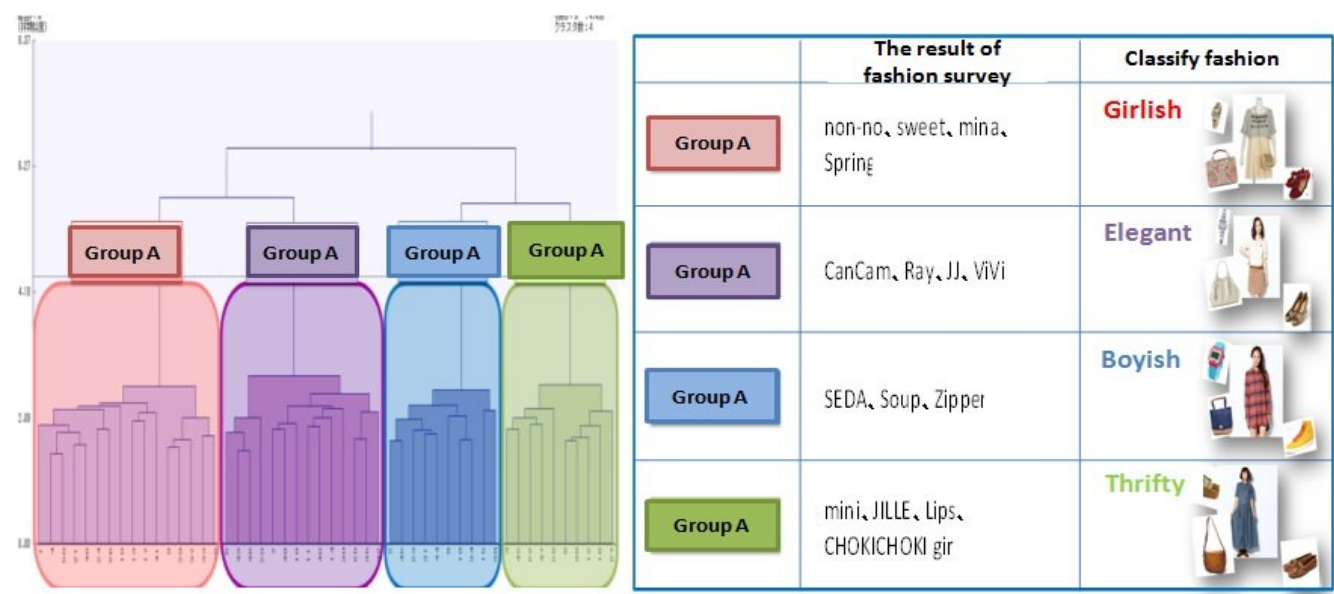

Fig. 8. (a) Classifying the subjects by their preferences; (b) The classification of the fashion
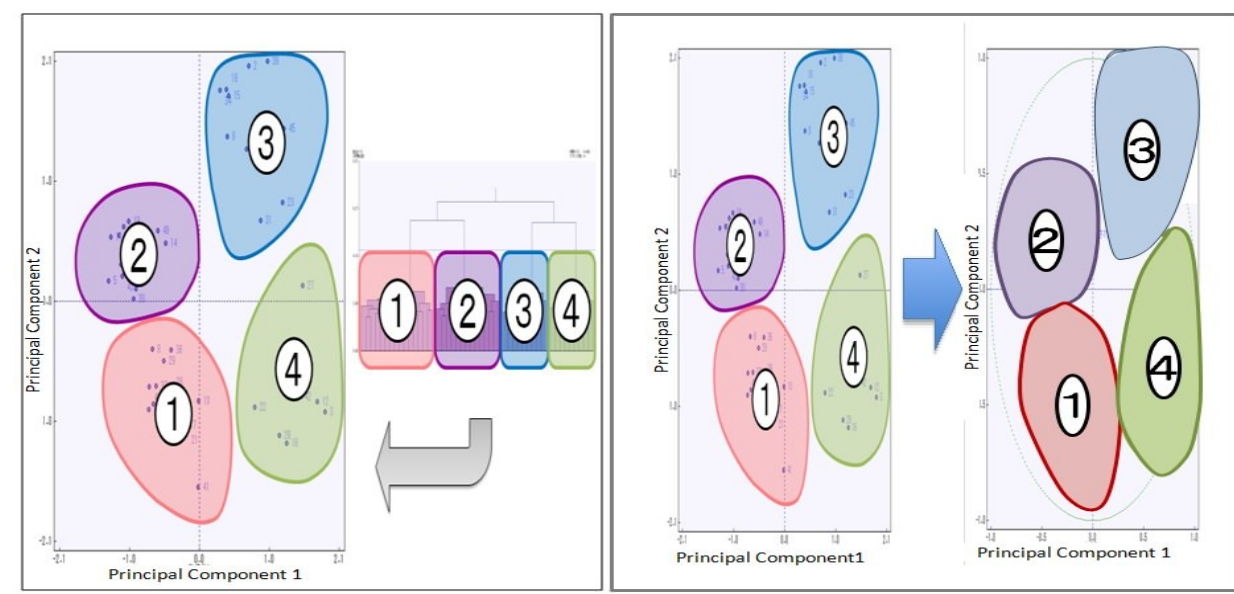

Fig. 9. (a) Cluster analysis and the principal component score scatter diagram.; (b) The principal component score scatter diagram and factor score scatter diagram

\subsection{Step 3. Color Matching}

Subsequently, preferred automobile colors were identified for each of the four groups as classified in the previous section ('Girlish', 'Elegant', 'Boyish' and 'Thrifty'), and design matching was undertaken based on AHP. First, in order to identify preferred automobile colors, subjects were shown PCCS hue rings, and were asked to answer " 1 " if they liked the hue and " 0 " if they disliked it (Fig 10 (a)). Subsequently, a hue ring liked by each group was identified using the Quantification Method Type III.

Fig 10 (b) indicates the scores of respective variants. According to the vertical axis, the positive area was defined as "high saturation", because tones with high saturation were concentrated in this area. Similarly, the negative area was defined as "low saturation". According to the horizontal axis, the positive area was defined as "low brightness", because tones with low brightness were concentrated in this area. Similarly, the negative area was defined as "high brightness". Referring to the grouping based on the consumer preference survey in the previous section, the tones preferred by each group could also be identified as indicated in Fig 11 (a). The 'Girlish' group preferred light grayish, light and soft tones. The 'Elegant' group liked dull, deep and grayish tones. The 'Boyish' group liked vivid, soft and dull tones, and the 'Thrift' group preferred vivid, bright and strong colors. These results also seem reasonable from the viewpoint of their respective preferred fashion styles. Because the 'Girlish' group likes soft and cute clothes, the 'Boyish' group prefers sporty and/or standard items, the 'Elegant' group likes chic and classy clothes, and the 'Thrift' group loves unique items, the classification above can be deemed appropriate.

Subsequently, a questionnaire survey by the scale of seven was conducted concerning colors contained in the identified hue rings, and colors with high mean values were included in the scope of matching. Fig 11 (b) indicates the selected colors.

Finally, AHP analysis for matching was conducted for the colors selected for each group, in the order of priority of parts (body, seats, and front panel in this order). The aim for AHP was the matching of automobile colors. The perceptional keywords for each group, as identified in 3.2, were used as the relevant parameters. Colors selected for each group were used as alternatives. The following analysis process is described taking the 
'Girlish' group as an example. First, the body color was determined. As Fig 12 (a) indicates, Alternative 2 was selected as the body color, because its significance was the highest. In the subsequent process, the selected body color was set while the seat color was determined. As Fig 12 (b) indicates, Alternative 5 was selected as the seat color, because its significance was the highest. Finally, the selected combination of body color and seat color was set while the front panel color was determined. As Fig 13 (a) indicates, Alternative 2 was selected as the front panel color, because it indicated the largest value. Through these steps, automobile design matching has been determined for the 'Girlish' group. In the same manner, the respective color matching for 'Elegant', 'Boyish' and 'Thrift' was analyzed and determined, as indicated in Fig 13 (b).
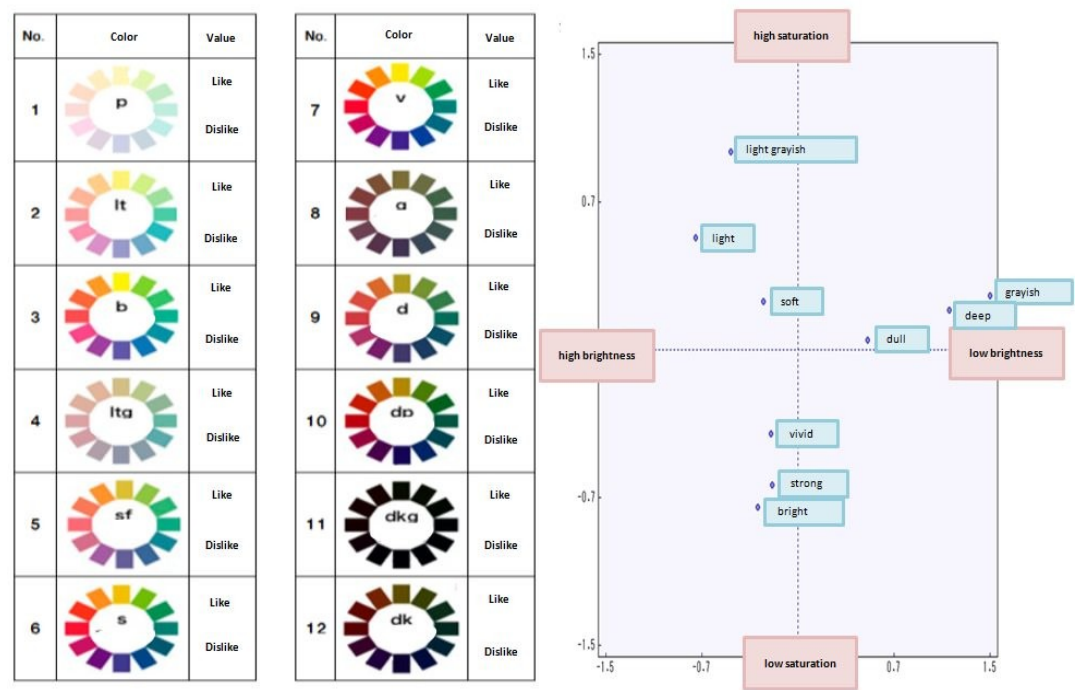

Fig. 10. (a) A questionnaire of hue rings; (b) The scores of respective variants on the Quantification Method Type III
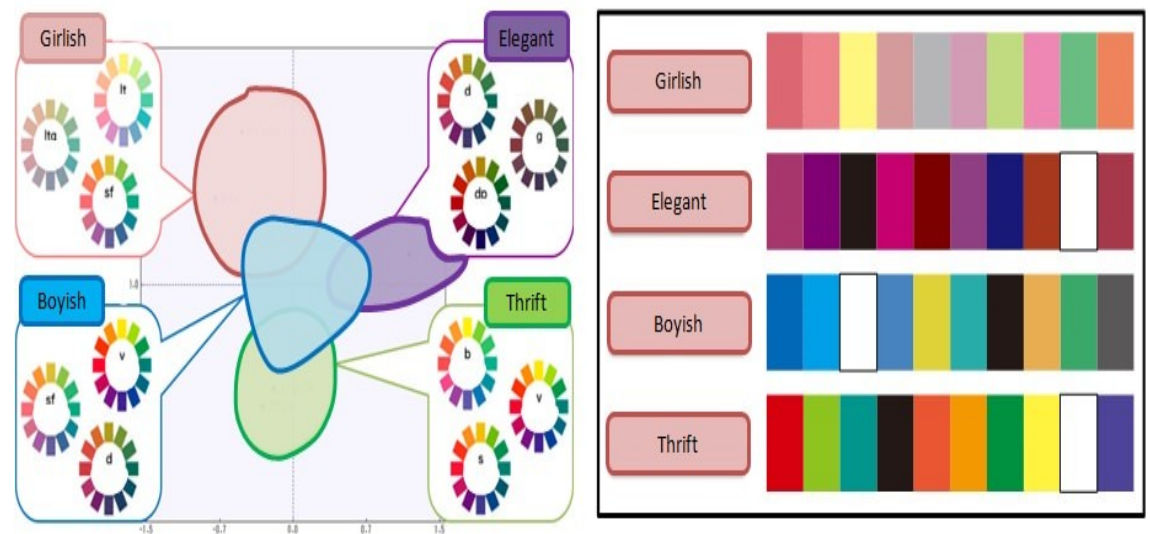

Fig. 11.(a) The classification of hue rings by each groups; (b) The color of the scope of matching
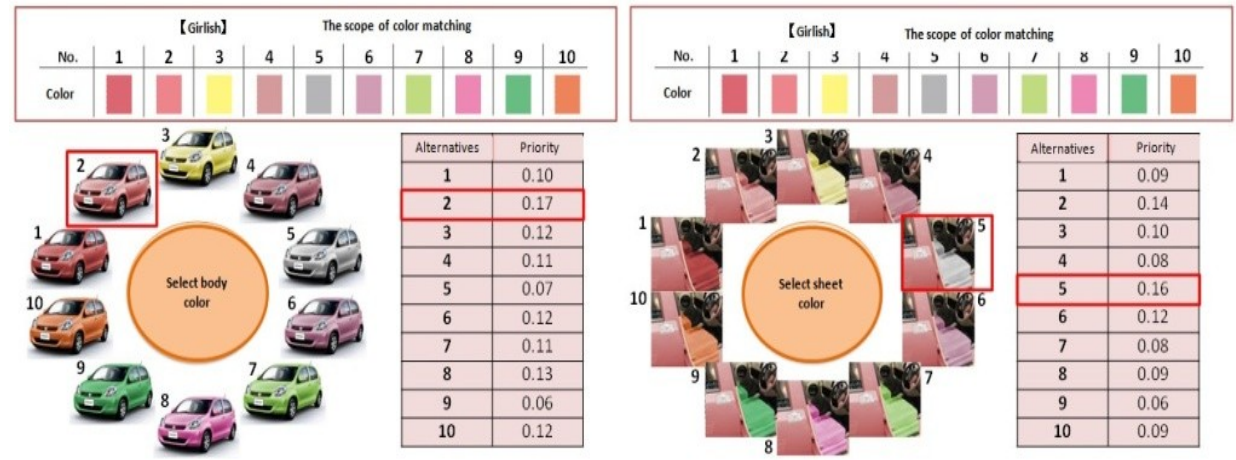

Fig. 12. (a)The selected body color; (b) The selected seat color 

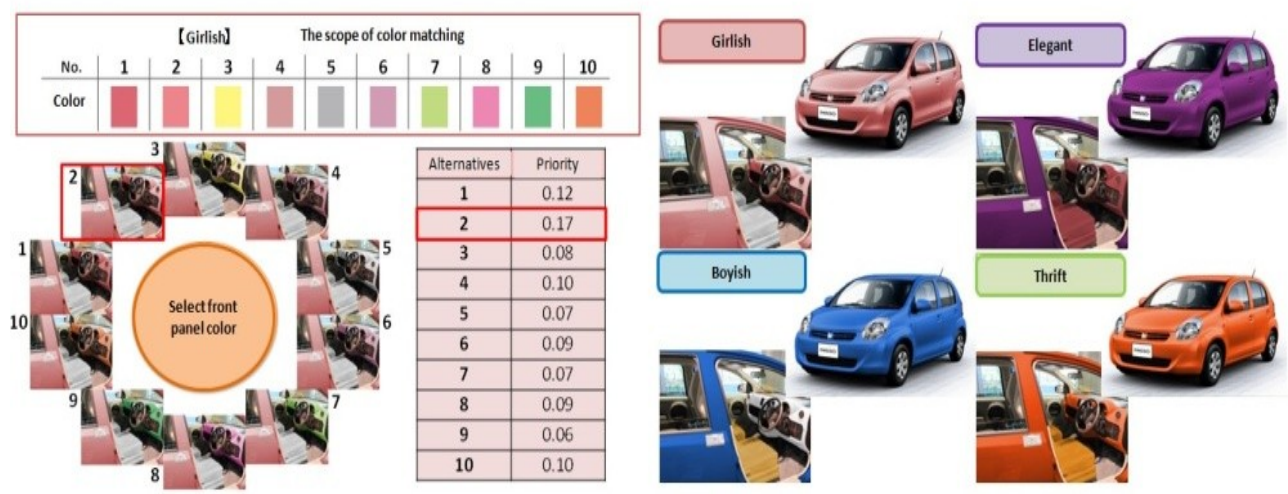

Fig. 13. (a) The selected front panel color; (b) The respective color matching

\subsection{Verification}

Verification was undertaken to check that the respective matching as identified through analysis, and its influence on consumer perception, would be practically useful. The color matching for verification was compared to the existing color matching of the Passo. A questionnaire survey by the scale of seven was conducted to identify the color matching with the highest mean value among respondents. The following process is described by using the 'Girlish' group as an example. Respondents were asked to evaluate the existing car color line and the color matching developed through ACMM by ranking them on a scale of seven, to see how effectively the intended perceptions were attained. As Fig 14 indicates, the color matching based on ACMM obtained high evaluations (using the questionnaire survey). Colors for the other groups were also verified in the same manner, all leading to high evaluations. Thus it was verified that the intended perceptions were attained through color matching based on ACMM. This model and the resulting color matching, as created by the authors, were acknowledged by the design institute of Automobile Manufacturer A to a certain extent.

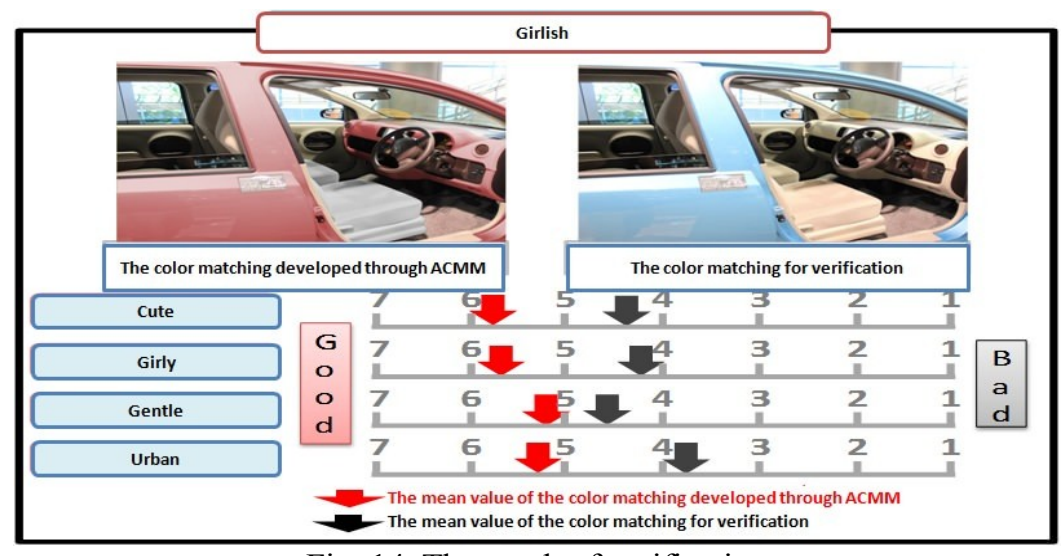

Fig. 14. The result of verification

\section{Conclusion}

The authors have constructed ACMM as a model for matching automobile exterior and interior colors, making use of physiological measurements and statistical science. The effectiveness of the resulting model has been partly verified, taking Japanese females in their $20 \mathrm{~s}$ as the scope of application. In future studies, application of ACMM will be expanded to other age groups and consumers in other countries.

\section{References}

[1] Amasaka K. Constructing a Customer Science Application System "CS-CIANS"- Development of a Global Strategic Vehicle "Lexus" Utilizing New JIT -. WSEAS Transactions on Business and Economics;2005, Vol.2, pp.135-142.

[2] Takimoto H, Ando T, Yamaji M, Amasaka K. The Proposal and Validity of the Customer Science Dual System-The Key to Corporate Management Innovation. China-USA Business Review;2010, Vol.9, No.3, pp.29-38.

[3] Amasaka K, Nagaya A, Shibata W. Studies on Design SQC with the Application of Science SQC -Improving of Business Process Method for Automotive Profile Design-. Japanese Journal of Sensory Evaluation;1990, Vol.3, No.1, pp.21-29.

[4] Takemura, K. Consumer Decision Process - The Japanese Journal of Psychonomic Science ; 2009 Vol. 28, No. 1, pp. 147-155.

[5] Amasaka K. New Japan Production Model, An Advanced Production Management Principle. The International Business \& Economics Research Journa;2007, Vol.6, No. 7, pp.67-79.

[6] Kawasumi M, Tanaka E. Online survey for color design of automotive rear combination lamp. Special Issue 41th Annual Meeting; 2010,pp118-119. 
[7] Asami H, Owada H, Murata Y, Takebuchi S, Amasaka K. The A-VEDAM Model for Approaching Vehicle Exterior Design. Journal of Business Case Studie;2011, Vol. 7, No. 5,.pp.1-8.

[8] Satake, I., Ando, K., Kuwano, K., Sato, T., Hattori, H. and Kajiwara, K. Study on Relationship between Automotive Exterior Color and Automotive Shape Category -J. Color Sci. Assoc. Jpn; 2004, Vol. 28, No. 2, pp. 102-110.

[9] Yoshida, T. Evolution and Future Trends of Paint Color for Automobiles, Color Designs and Painting Schemes -J. Soc. Autom. Eng. Jpn; 2003, Vol. 57, No. 5, pp. 4-9.

[10] Fujieda, S., Masuda, Y. and Nakahata, A. Development of Automotive Color Designing Process -J. Soc. Autom. Eng. Jpn; 2007,Vol. 61, No. 6, pp. 79-84.

[11] Asakura S, Kanke R, Tomimatsu K, Amasaka K. A studey of an automobile intereer and extereer color matching. Aoyamagakuin University;2012. 